\title{
Sistem Rekrutmen Tenaga Pendidik dan Kependidikan pada Pendidikan Formal di Yayasan Pondok Pesantren Mukhtar Syafa'at Banyuwangi
}

\author{
Nur Khafid Nizam Fahmi ${ }^{1}$, Ahmad Zahidin ${ }^{2}$ \\ e-mail :fahminizam26@gmail.com ${ }^{1}$,zahid96jhe@gmail.com ${ }^{2}$ \\ Prodi Manajeman Pendidikan Islam \\ Institut Agama Islam Darussalam Blokagung Banyuwangi
}

\begin{abstract}
The objectives of this study were 1) to study the process of recruiting educators and education personnel in formal education at the Mukhtar Syafa'at Blokagung Islamic Boarding School, 2) to find out researchers and obstacles to the recruitment system for educators and education personnel in the formal education of the Mukhtar Syafa'at Islamic boarding school. blokagung. This type of research is quantitative descriptive using observation, interview instruments and documentation for data analysis techniques while the analysis uses miles and huberman. The results of the study included a) Teacher recruitment prioritizing santri and alumni of the Mukhtar Syafa'at Blokagung Islamic boarding school foundation, b) Educator and education recruitment was carried out centrally by the head of the education sector and the construction of the Mukhtar Syafa'at Blokagung Islamic boarding school foundation assisted by the foundation secretary, head of the field quality assurance and principal of each unit, c) Submission of non-permanent teacher decrees for 2 years as a test of teacher and employee loyalty.
\end{abstract}

Keywords: recruitment, teaching staff, and education staff

\begin{abstract}
Abstrak
Tujuan dari penelitian ini adalah 1) untuk mengetahui proses rekrutmen tenaga pendidik dan kependidikan pada pendidikan formal di pondok pesntren mukhtar syafa'at blokagung, 2) untuk mengetahui faktor pendukung dan penghambat sistem rekrutmen tenaga pendidik dan kependidikan pada pendidikan formal pondok pesantren mukhtar syafa'at blokagung. Jenis penelitian ini adalah deskriptif kuantitatifdenganmenggunakan observasi, instrumen wawancara dan dokumentasi untukteknik pengumpulan datasedangkan analisisnya menggunakan miles dan huberman. Hasil penelitian meliputi a) Rekrutmen guru mengutamakan santri dan alumni yayasan pondok pesantran Mukhtar Syafa'at Blokagung, b) Rekrutmen pendidik dan kependidikan dilaksanakan secara terpusat oleh kepala bidang pendidikan dan pengajaran yayasan pondok pesantren Mukhtar Syafa'at Blokagung dibantu oleh sekertaris yayasan, kepala bidang penjamin mutu dan kepala sekolah setiap unit, c) Penyerahan surat keputusan guru tidak tetap selama 2 tahun sebagai uji loyalitas guru dan karyawan.
\end{abstract} Kata kunci: rekrutmen, tenaga pendidik, dan tenaga kependidikan

Sistem Rekrutmen Tenaga Pendidik dan Kependidikan pada Pendidikan Formal di Yayasan Pondok Pesantren Mukhtar Syafa'at Blokagung Banyuwangi Nur Khafid Nizam Fahmi, Ahmad Zahidin 
JMPID ( Jurnal Manajemen Pendidikan Islam Darussalam )

Jurnal Manajemen Pendidikan Islam

Volume: 2, No: 2, September 2020

ISSN : 2722-7146 (online)

\section{A. Pendahuluan}

Sekolah sebagai suatu organisasi atau lembaga pendidikan merupakan sarana untuk melaksanakan proses pendidikan. Selain dijadikan sebagai sarana perkumpulan antara guru dan siswa juga sebagai suatu sistem yang terkonsep rapi di mana terjadi interaksi untuk menghasilkan pemahaman kepada siswa. Di sisi lain, sekolah merupakan sarana untuk mencetak sosok manusia yang berpendidikan tanpa mempertimbangkan latar belakang siswa yang telibatdidalamnya baik dari segi perekonomian, sosial maupun kebudaya anya. Perkembangan globalisasi yang begitu pesat sangatlah mempengaruhi pada lembaga pendidikan. Untuk mengikuti perkembangan yang ada selain dari sarana dan prasarana juga sangat berpengaruh pada tenaga pendidik dan kependidikanya. Tuntutan tanggung jawab membuat mereka harus berfikir kreatif untuk hasil yang sesuai dan selaras dengan tujuan. Mereka dipilih melalui seleksi yang sangat ketat. Pihak panitia dituntut untuk mampu merekrut dan menyeleksi calon pendidik dan tenaga kependidikan lainnya dengan baik.

Undang-undang Sistem Pendidikan Nasional (Sisdiknas) Nomor 20 Tahun 2003 bab I Ketentutan umum Pasal 1 nomor urut 5 menyebutkan bahwa Tenaga Kependidikan adalah anggota masyarakat yang mengabdikan diri dan diangkat untuk menunjang penyelenggaraan pendidikan.

Mulyasa (2010:81) berpendapat bahwa:

Tenaga kependidikan di sekolah harus ditujukan untuk memberdayakan tenaga-tenaga kependidikan secara efektif dan efesien untuk mencapai hasil yang optimal, namun tetap dalam kondisi yang menyenangkan. Sehubungan dengan itu, fungsi manajemen tenaga kependidikan di sekolah yang harus dilaksanakan guru dan kepala sekolah adalah menarik, mengembangkan, menggaji, dan memotivasi tenaga kependidikan guna mencapai tujuan pendidikan secara optimal; membantu tenaga kependidikan mencapai posisi dan standar perilaku; memaksimalkan perkembangan karier, serta meyelaraskan tujuan individu, kelompok, dan lembaga.

Sistem Rekrutmen Tenaga Pendidik dan Kependidikan pada Pendidikan Formal di Yayasan Pondok Pesantren Mukhtar Syafa'at Blokagung Banyuwangi Nur Khafid Nizam Fahmi, Ahmad Zahidin 
JMPID ( Jurnal Manajemen Pendidikan Islam Darussalam )

Jurnal Manajemen Pendidikan Islam

Volume: 2, No: 2, September 2020

ISSN : 2722-7146 (online)

Kegiatan perekrutan selain untuk memenuhi posisi yang kosong juga untuk memberikan yang terbaik bagi siswa dan kedisiplinan untuk para tenaga pendidik dan kependidikan demi tujuan dari lembaga.

Yayasan Pondok Pesantren Mukhtar Syafa'at merupakan salah satu lembaga pendidikan yang berada di Dusun Blokagung Desa Karangdoro Kecamatan Tegalsari Kabupaten Banyuwangi. Dalam proses rekrutmennya Yayasan Pondok Pesantren mukhtar syafa'at menerima lamaran dari calon guru dan karyawan untuk kemudian ditindaklanjuti oleh Bidang pengembangan pendidikan formal Yayasan karena bidang tersebut yang menangani perekrutan guru dan karyawan pada lembaga pendidikan formal Yayasan Pondok Pesantren Mukhtar Syafa'at.

\section{B. Rumusan Masalah}

1 Bagaimanakah proses rekrutmen tenaga pendidik dan kependidikan pada pendidikan formal MA Unggulan Mukhtar Syafa'at dan SMK Mukhtar Syafa'at di Yayasan Pondok Pesantren Mukhtar Syafa'at Blokagung Tegalsari Banyuwangi tahun ajaran 2019/2020?

2 Apa sajakah faktor pendukung dan penghambat sistem rekrutmen tenaga pendidik dan kependidikan pada pendidikan formal MA Unggulan Mukhtar Syafa'at dan SMK Mukhtar Syafa'at di Yayasan Pondok Pesantren Mukhtar Syafa'at Blokagung Tegalsari Banyuwangi tahun ajaran 2019/2020?

\section{Tujuan Penelitian}

1 Untuk mengetahui proses rekrutmen tenaga pendidik dan kependidikan pada pendidikan formal MA Unggulan Mukhtar Syafa'at dan SMK Mukhtar Syafa'atdi Yayasan Pondok Pesantren Mukhtar Syafa'atBlokagungTegalsari Banyuwangi tahun ajaran 2019/2020

2 Untuk mengetahui faktor pendukung dan penghambat proses rekrutmen tenaga pendidik dan kependidikan formal MA Unggulan Mukhtar Syafa'at dan SMK Mukhtar Syafa'at di Yayasan Pondok Pesantren Mukhtar

Sistem Rekrutmen Tenaga Pendidik dan Kependidikan pada Pendidikan Formal di Yayasan Pondok Pesantren Mukhtar Syafa'at Blokagung Banyuwangi Nur Khafid Nizam Fahmi, Ahmad Zahidin 
JMPID ( Jurnal Manajemen Pendidikan Islam Darussalam )

Jurnal Manajemen Pendidikan Islam

Volume: 2, No: 2, September 2020

ISSN : 2722-7146 (online)

Syafa'at Blokagung Tegalsari Banyuwangi tahun ajaran 2019/2020

\section{Tinjauan Pustaka}

1 Pengertian Sistem

Dalam KBBI (Kamus Besar Bahasa Indonesia) Sistem adalah perangkat atau unsur yang secara teratur saling berkaitan sehingga membentuk suatu totalitas, atau sebuah susunan yang teratur dari pandangan, teori, asas, dan sebagainya.

Darmawan dan Nur Fauzi (2016:4) juga mengemukakan bahwa "kita bisa mendefinisikan sistem sebagai kumpulan dari bagian apapun baik fisik yang saling berhubungan satu sama lain dan bekerja sama untuk mencapai tujuan”. Pendapat lain, menurut Mc Leond dalam Rochaety (2009:3) sistem yaitu "sekelompok elemen yang terintegrasi untuk mencapai suatu tujuan".

Berdasarkan beberapa definisi diatas, maka dapat disimpulkan bahwa pengertian sebuah sistem adalah kumpulan atau seperangkat alat dari suatu butir-butir pemahaman yang terintegrasi dan bekerja guna mencapai suatu tujuan tertentu sesuai kesepakatan yang telah disepakati.

2 Pengertian Rekrutmen

Sofyandi (2008: 100) menyatakan bahwa "rekrutmen merupakan proses penarikan orang-orang atau pelamar yang mempunyai minat dan kualifikasi yang tepat untuk mengisi kekosongan posisi atau jabatan tertentu".

Menurut T. Hani Handoko(2001: 65) mengemukakan bahwa "penarikan (rekrutmen) adalah proses pencarian dan pemikatan para calon karyawan (pelamar) yang mampu untuk melamar sebagai karyawan".

Pendapat dari Hadari Nawawi (2005: 169) mengemukakan bahwa "rekrutmen adalah proses mendapatkan sejumlah calon tenaga

Sistem Rekrutmen Tenaga Pendidik dan Kependidikan pada Pendidikan Formal di Yayasan Pondok Pesantren Mukhtar Syafa'at Blokagung Banyuwangi Nur Khafid Nizam Fahmi, Ahmad Zahidin 
JMPID ( Jurnal Manajemen Pendidikan Islam Darussalam )

Jurnal Manajemen Pendidikan Islam

Volume: 2, No: 2, September 2020

ISSN : 2722-7146 (online)

kerja yang memiliki kualifikasi untuk jabatan atau pekerjaan di lingkungan suatu organisasi atau perusahaan".

Pasal 11 ayat 2 undang-undang nomer 63 tahun 2005 tentang sistem manajeman sumber daya manusia. Rekrutmen dan seleksi pegawai merupakan kegiatan yang terencana dan sistematis untuk mendapatkan pegawai sesuai dengan kebutuhan komisi agar dapat mendukung pencapain tujuan-tujuan komisi.

beberapa pendapat di atas pemahaman rekrutmen yaitu rekrutmen merupakan proses penarikan calon karyawan, guru, pekerja dari para pelamar yang berminat,mempunyai skill, mampu, bertanggung jawab dan berkualitas serta siap menjalankan tugas dengan ketentuan atau persyaratan yang dibutuhkan pada posisi yang kosong.

3 Pengertian Tenaga Pendidik

Menurut Saiful (2013: 21) Guru/tenaga pendidik adalah "semua orang yang berwenang danBertanggung jawab terhadap pendidikan murid-murid, baik secara individualataupun klasikal, baik di sekolah maupun di luar sekolah".

Ibrahim Bafadal (2008: 58) berpendapat "Dalam rangka mendapatkan calon tenaga pendidik yang profesional, memenuhi kualifikasi dan mejanjikan untuk menduduki posisi tertentu tidaklah mudah".

Ibrahim Bafadal (2008: 65) berpendapat bahwa Ada beberapa prinsip yang harus di pegang teguh dalam perencanaan dan perekrutan tenaga pendidik diantaranya:

1 Rekrutmen tenaga pendidik harus direncanakan secara matang agar dapat memenuhi kebutuhan

2 Rekrtmen tenaga pendidik harus dilaksanakan secara objektif artinya panitia menyeleksi pegawai baru, menetapkan pelamar yang lulus dan pelamar yang tidak lulus secara objektif

Sistem Rekrutmen Tenaga Pendidik dan Kependidikan pada Pendidikan Formal di Yayasan Pondok Pesantren Mukhtar Syafa'at Blokagung Banyuwangi Nur Khafid Nizam Fahmi, Ahmad Zahidin 
JMPID ( Jurnal Manajemen Pendidikan Islam Darussalam )

Jurnal Manajemen Pendidikan Islam

Volume: 2, No: 2, September 2020

ISSN : 2722-7146 (online)

Agar didapatkan calon yang profesional, sebaiknya materi seleksi pegawai baru harus komprehensif mencakup semua aspek peryasaratan yang harus dimiliki oleh calon tenaga pendidik.

4 Pengertian Tenaga Kependidikan

Sutrisno Edy (2009: 46) berpendapat bahwa:

"Sebuah proses rekrutmen dimulai dengan penarikan calon dan berahir sampai lamaran mereka diterima. Tahap berikutnya adalah mencari calon sebanyak jumlah yang diperlukan yang akan deseleksi, mencari orang yang dianggap paling memenuhi syarat untuk mengisi lowongan."

Menurut UUSPN No.20 Tahun 2003 khususnya bab I Pasal 1 ayat (5) menyebutkan bahwa tenaga kependidikan adalah anggota masyarakat yang mengabdikan diri dan diangkat untuk menunjang penyelenggaraan pendidikan.

rekrutmen tenaga kependidikan adalah proses pencarian karyawan lembaga dengan syarat-syarat tertentu yang dibutuhkan pada posisi yang kosong yang dianggap paling memenuhi syarat dan bertanggung jawab pada posisi jabatannya.

5 Faktor-Faktor yang Memengaruhi Sistem Rekrutmen

Kegiatan rekrutmen tenaga pendidik dan tenaga kependidikan berjalan lancar dengan adanya kegiatan lain yang mendukung kesuksesan perekrutan, dengan hal-hal tersebut bisa memberikan motivasi dan semangat kepada pelaku perekrutan untuk menjalankan tugas, mencari dan menyeleksi para calon-calon pendidik dan kependidikan.

Menurut Malayu S. P. Hasibuan (2007) "agar proses perekrutan berhasil, maka perusahaan perlu menyadari berbagai kendala yang bersumber dari organisasi, pelaksana penarikan, dan lingkungan eksternal.”

\section{E. Metode Penelitian}

1 Jenis Penelitian

Sistem Rekrutmen Tenaga Pendidik dan Kependidikan pada Pendidikan Formal di Yayasan Pondok Pesantren Mukhtar Syafa'at Blokagung Banyuwangi Nur Khafid Nizam Fahmi, Ahmad Zahidin 
JMPID ( Jurnal Manajemen Pendidikan Islam Darussalam )

Jurnal Manajemen Pendidikan Islam

Volume: 2, No: 2, September 2020

ISSN : 2722-7146 (online)

Dalam penelitian ini, masalah yang akan diteliti tentang sistem rekrutmen tenaga pendidik dan kependidikan pada pendidikan formal di yayasan pondok pesantren mukhtar syafa'at. Sesuai dengan judul tersebut, penelitian ini memiliki jenis penelitian deskriptif kualtitatif. Penelitian deskriptif kualtitatif ialah penelitian yang bersifat mendeskripsikan hasil penelitian sebagai jawaban dari rumusan masalah penelitian (Sugiyono, 2016:21).

\section{Lokasi Penelitian}

Penelitian ini dilaksanakan di Yayasan Pondok Pesantren Mukhtar Syafa'at Blokagung Banyuwangi.

\section{Sumber Data}

Sumber data yang digunakan dalam penelitian ini ada dua yaitu: sumber data primer dan sekunder. Sumber data primer adalah sumber data yang dipakai oleh peneliti dalam mengumpulkan data utama yakni pihak yayasan, kepala sekolah, dan guru sebagai narasumber utama dan observasi langsung di lembaga untuk mendapatkan data berupa kondisi nyata masalah penelitian. Sedangkan sumber data sekunder didapat dari bagian tata usaha untuk mendapatkan data terkait administrasi dan data pendukung penelitian lainnya.

4 Teknik Pengumpulan Data

Dalam penelitian ini teknik pengumpulan data menggunakan 3 tahapan sesuai dengan pendapat Sugiyono (2015: 309) menyatakan "Dalam penelitian kualitatif pengumpulan data dilakukan pada natural setting (kondisi yang alami), sumber data primer, dan teknik pengumpulan data lebih banyak pada observasi berperan serta, wawancara mendalam, dan dokumentasi”.

5 Analisis Data

Analisis data dalam penelitian ini menggunakan analisis Miles dan Huberman dengan tiga tahapan yang harus dikerjakan dalam menganalisis data penelitian kualitatif, yaitu reduksi data, penyajian data dan penarikan kesimpulan.

Sistem Rekrutmen Tenaga Pendidik dan Kependidikan pada Pendidikan Formal di Yayasan Pondok Pesantren Mukhtar Syafa'at Blokagung Banyuwangi Nur Khafid Nizam Fahmi, Ahmad Zahidin 


\section{F. Hasil Penelitian}

Sistem rekrutmen guru dan karyawan pendidikan formal Yayasan Pondok Pesantren Mukhtar Syafa'at Blokagung. Berikut beberepa tahapan proses perekrutan tenaga pendidik dan kependidikan di Yayasan Pondok Pesantren Mukhtar Syafa'at Blokagung:

a. Pencarian tenaga pendidik mengutamakan santri dan alumni, dan tenaga kependidikan fokus pada santri

Kriteria tenaga pendidik dan kependidikan dari kalangan santri yakni sesuai dengan persyaratan dari lembaga dan tidak terikat dengan kegiatan madrasah diniyah (sudah menyelesikan sekolah diniyahnya) karena ditakutkan kegiatan di lembaga pendidikan formal mengganggu sekolah diniyahnya. Selain itu persyaratan yang wajib tetap diutamakan seperti berkas-berkas umum yang harus dibawa oleh pelamar.

b. Kriteria tenaga pendidik dan kependidikan dari kalangan alumni yayasan pondok pesantren Mukhtar Syafa'at Blokagung

Alasan perekrutan tenaga pendidik dan kependidikan dari kalangan alumni tidak jauh berbeda dengan perekrutan dari kalangan santri, namun pada alumni tidak diwajibkan lulus diniyah. Perekrutan dari kalangan alumni selain alasan di atas juga karena alumni mempunyai rasa memiliki yang lebih besar dan mengerti keadaan di yayasan.

c. Pelaksanaan perekrutan dilaksanakan terpusat di kantor yayasan pondok pesantren Mukhtar Syafa'at Blokagung

Pelaksanaan perekrutan tenaga pendidik dan kependidikan perlu adanya langkah-langkah yakni dari tahap perencanaan dan diakhiri dengan pelamar diterima di yayasan. Agar proses perekrutan berjalan baik dan menghasilkan tenaga pendidik dan kependidikan yang sesuai harapan. 
JMPID ( Jurnal Manajemen Pendidikan Islam Darussalam )

Jurnal Manajemen Pendidikan Islam

Volume: 2, No: 2, September 2020

ISSN : 2722-7146 (online)

Perencanaan kebutuhan tenaga pendidik dan kependidikan di bahas pada saat rapat kepala bidang pendidikan bersama kepala sekolah/madrasah tiap-tiap unit di awal tahun. Secara teknisnya setiap kepala sekolah/madrasah mengajukan membutuhkan tenaga pendidik dan kependidikan dengan mata pelajaran tertentu atau posisi yang kosong bagi tenaga pendidik dan juga kapan dibutuhkanya.

d. Tim-tim perekrutan tenaga pendidik dan tenaga kependidikan tim-tim-tim rekrutmen berasal dari pihak yayasan yakni ketua yayasan, kepala bidang penjamin mutu, sekertaris yayasan, bendahara yayasan sebagai pendukung keuangan, Kepala bidang pendidikan, kepala sekolah, wakil kepala sekolah, dan ketua tata usaha mengumpulkan kebutuhan pendidik dan kependidikan yang diperlukan dengan melalui pencarian yang direkomendasikan dari guru atau karyawan lama, pengurus pondok, orang-orang terdekat atau mengambil dari surat lamaran yang sudah masuk.

\section{G. Pembahasan}

1. Sistem Rekrutmen Tenaga Pendidik dan Kependidikan pada Pendidikan Formal di Yayasan Pondok Pesantren Mukhtar Syafa'at

Rekrutmen guru mengutamakan santri dan alumni yayasan pondok pesantran Mukhtar Syafa'at Blokagung sebagai pendidik dan kependidikan yang berlandaskan Ahlussunnah Wal Jamaah. Rekrutmen guru dan kryawan di Yayasan Pondok Pesantren Mukhtar Syafa'at Blokagung dengan memprioritaskan dari kalangan internal dari lembaga. Kalangan internal yang dimaksud disini adalah santri yang sudah menyelesaikan pendidikan Madrasah Diniyah tingkat Ulya di yayasan pondok pesantren Mukhtar Syafa'at Blokagung.

Rekrutmen guru dan karyawan dilaksanakan secara terpusat oleh kepala bidang pendidikan dan pengajaran yayasan pondok pesantren mukhtar syafa'at Blokagung dengan kebutuhan guru dan karyawan Sistem Rekrutmen Tenaga Pendidik dan Kependidikan pada Pendidikan Formal di Yayasan Pondok Pesantren Mukhtar Syafa'at Blokagung Banyuwangi Nur Khafid Nizam Fahmi, Ahmad Zahidin 
JMPID ( Jurnal Manajemen Pendidikan Islam Darussalam )

Jurnal Manajemen Pendidikan Islam

Volume: 2, No: 2, September 2020

ISSN : 2722-7146 (online)

dirumuskan melalui rapat dengan kepala sekolah seluruh unit setiap awal tahun pembelajaran.

Rekrutmen guru yayasan dirumuskan sesuai dengan kebutuhan guru setiap unit yang diketahui dengan adanya rapat rutinan antara pihak yayasan dan kepala Sekolah/Madrasah seluruh unit. Sehingga guru yang masuk di yayasan sesaui dengan bidang keahlian yang dibutuhkan oleh yayasan. Rekrtmen guru dan karyawan sesuai dengan bidang keahlian yang dimiliki dan posisi yang kosong dibagian operasional yang mana kebutuhan tenaga pendidik dan kependidikan oleh yayasan sesuai dengan yang diungkapkan oleh L. Gaol (2014: 375) mengatakan bahwa agen-agen penempatan tenaga kerja. Agen ini sebagai penyalur kebutuhan antara pencari tenaga kerja dan pelamar pekerjaan.

Penetapan spesifikasi KSA (knowledge, skill and attitude) dan etika, pengetahuan dan kemampuan yang dimiliki guru bidang mata pelajaran tertentu. Etika yang dimiliki seorang guru merupakan hal penting dalam lingkup pendidikan karena guru adalah figur yang dicontoh oleh peserta didik,tenaga kependidikan juga tidak kalah pentingnya untuk menjalankan kegiatan pengarsipan, kegiatan pendukung tenaga pendidik dan bagian ke-TU-an lainya. untuk itu diperlukan adanya penetapan spesifikasi yang tertulis sebagai suatu persyaratan bagi calon guru dan karyawan yang mengajar dan pengabdian bagian administrasi di Yayasan. Penetapan etika tertentu sebagai syarat rekrutmen sesuai dengan yang diungkapkan oleh Bafadal (2003: 87) dalam Kamaruddin (2012: 4) Penetapan persyaratanpersyaratan untuk melamar menjadi guru.

Kualifikasi guru disesuaiakan dengan kebutuhan setiap unit yang sudah diajukan oleh kepala sekolah, sehingga guru yang masuk sesuai dengan keahlian yang dibutuhkan oleh masing-masing unit. Rekrutmen guru sesuai bidang keahlian yang dimiliki oleh sekolah sesuai dengn Yng diungkapkan oleh L. Gaol (2014: 375) yang mengatakan bahwa Agen-

Sistem Rekrutmen Tenaga Pendidik dan Kependidikan pada Pendidikan Formal di Yayasan Pondok Pesantren Mukhtar Syafa'at Blokagung Banyuwangi Nur Khafid Nizam Fahmi, Ahmad Zahidin 
JMPID ( Jurnal Manajemen Pendidikan Islam Darussalam )

Jurnal Manajemen Pendidikan Islam

Volume: 2, No: 2, September 2020

ISSN : 2722-7146 (online)

agen penempatan tenaga kerja. Agen ini sebagai penyalur kebutuhan antara pencari tenaga kerja dan pelamar pekerjaan.

Penyerahan surat keputusan guru tidak tetap selama 2 tahun sebagai uji loyalitas guru di yayasan. Salah satu bentuk apresiasi yang dilakukan pengelola Yayasan atas prestasi kineja guru tidak tetap dengan pemberian pengakuan melalui adanya surat keputusan menjadi guru dan karyawan tetap di yayasan pondok pesantren mukhtar syafa'at Blokagung. Rekrutmen guru dengan mempertimbangkan uji loyalitas kepribadian sesuai dengan teori yang diungkapkan oleh Siagian (2016: 103) yang mengungkapkan bahwa Kebijaksanaan promosi dari anggota yang sudah menjadi karyawan organisasi sehingga dapat meningkatkan kepuasan kerja, loyalitas kepada organisasi sehingga mengurangi keinginan pindah organisasi yang lain.

2. Faktor Pendukung dan Penghambat Sistem Rekrutmen Pendidik di Yayasan Pondok Pesantren Mukhtar Syafa'at Blokagung

Faktor-faktor yang dapat mendukung meliputi kekuatan dan peluang yang ada di Yayasan Pondok Pesantren Mukhtar Syafa'at yaitu:

a. Adanya Santri yang sudah memiliki kualifikasi akademik S1 sehingga dapat menjadi salah satu bukti legalitas terkait kemampuannya..

b. Statement masyarakat terhadap pondok pesantren sebagai Pondok Pesantren yang sudah mempunyai nama di kalangan masyarakat membuat pesantren tidak perlu melakukan publikasi untuk mencari calon guru maupun karyawan sperti teori yang diungkapkan oleh L. Gaol (2014: 375) yang mengatakan bahwa agen- agen penempatan tenaga kerja. Agen ini sebagai penyalur kebutuhan antara pencari tenaga kerja dan pelamar pekerjaan.

Faktor-faktor yang dapat menghambat meliputi kelemahan dan tantangan yang ada di Yayasan Pondok Pesantren Darussalam yaitu:

a. Adanya Guru yang Berkompen tidak sesuai dengan loyalitas yang ditentukan Yayasan Pondok Pesantren Mukhtar Syafa'at. Hal ini

Sistem Rekrutmen Tenaga Pendidik dan Kependidikan pada Pendidikan Formal di Yayasan Pondok Pesantren Mukhtar Syafa'at Blokagung Banyuwangi Nur Khafid Nizam Fahmi, Ahmad Zahidin 
JMPID ( Jurnal Manajemen Pendidikan Islam Darussalam )

Jurnal Manajemen Pendidikan Islam

Volume: 2, No: 2, September 2020

ISSN : 2722-7146 (online)

tidak sesuia dengan teori yang diungkapkan oleh L. Gaol (2014: 375) yang mengatakan bahwa agen-agen penempatan tenaga kerja. Agen ini sebagai penyalur kebutuhan antara pencari tenaga kerja dan pelamar pekerjaan.

b. Statement masyarakat yang menjadikan Pondok Pesantren sebagai pilihan kedua (second choice) karena pandangan sebagian masyarakat masih kepada lembaga pendidikan yang non pesantren lebih baik dibandingkan dengan pendidikan yang berbasis pesantren.

\section{H. Kesimpulan}

\section{Sistem rekrutmen tenaga pendidik dan kependidikan di Yayasan} Pondok Pesantren Mukhtar Syafa'at Blokagung

Sistem rekrutmen tenagapendidikdankependidikan Di Yayasan Pondok Pesantren MukhtarSyafa'at Meliputi:

a. Rekrutmen guru mengutamakan santri dan alumni yayasan pondok pesantran Darussalam Blokagung sebagai pendidik yang berlandaskan Ahlussunnah Wal Jamaah sesuai visi misi yayasan

b. Rekrutmen guru sesuai dilaksanakan secara terpusat oleh kepala bidang pendidikan dan pengajaran yayasna pondok pesantren Darussalam Blokagung dengan kebutuhan guru dirumuskan melalui rapat dengan kepala sekolah seluruh unit setiap awal tahun pembelajaran dengan merencanakan

1 Rekrutmen guru yayasan dirumuskan sesuai dengan kebutuhan guru setiap unit yang diketahui dengan adanya rapat rutinan antara pihak yayasan dan kepala sekolah/madrasah seluruh unit.

2 Penetapan spesifikasi etika, pengetahuan dan kemampuan (knowledge, skill and attitude "KSA") guru bidang mata

Sistem Rekrutmen Tenaga Pendidik dan Kependidikan pada Pendidikan Formal di Yayasan Pondok Pesantren Mukhtar Syafa'at Blokagung Banyuwangi Nur Khafid Nizam Fahmi, Ahmad Zahidin 
JMPID ( Jurnal Manajemen Pendidikan Islam Darussalam )

Jurnal Manajemen Pendidikan Islam

Volume: 2, No: 2, September 2020

ISSN : 2722-7146 (online)

pelajaran tertentu secara terpusat oleh Yayasan agar yayasan mengetahui kebutuhan tenaga pendidik yang diharapkan setiap unit dan sejauh mana keahlian calon guru baru

3 Publikasi dengan metode tertutup melalui teman, kerabat dekat maupun guru yayasan yang bersifat rekomendasi sehingga lebih memanfaatkan orang dalam

4 Kualifikasi guru sesuai kebutuhan sekolah disesuaikan dengan riwayat pendidikan terakhir dan rekomendasi yang diajukan unit kepada yayasan

5 Penyerahan surat keputusan guru tidak tetap selama 2 tahun sebagai uji loyalitas guru di yayasan.

\section{Faktor Pendukung dan Penghambat dalam Sistem Rekrutmen Pendidik di Yayasan Pondok Pesantren Mukhtar Syafa'at}

a. Faktor-faktor yang dapat mendukung meliputi kekuatan dan peluang yang ada di Yayasan Pondok Pesantren Mukhtar Syafa'at yaitu:

(1) Adanya Santri yang sudah memiliki kualifikasi akademik S1.

(2) Statemen masyarakat terhadap pondok pesantren sebagai Pondok Pesantren yang telah mempunyai mempunyai nama di kalangan masyarakat umum membuat pesantren tidak perlu melakukan publikasi untuk mencari calon guru.

b. Faktor-faktor yang dapat menghambat meliputi kelemahan dan tantangan yang ada di Yayasan Pondok Pesantren Mukhtar Syafa'at yaitu:

(1) Adanya Guru yang Berkompeten tidak sesuai dengan loyalitas yang ditentukan Yayasan Pondok Pesantren Mukhtar Syafa'at.

(2) Statement masyarakat yang menjadikan Pondok Pesantren sebagai pilihan kedua (second choice).

\section{Daftar Pustaka}

Bafadal, Ibrahim. 2008. Peningkatan Profesionalisme Guru Sekolah Dasar.Jakarta: Bumi Aksara.

Sistem Rekrutmen Tenaga Pendidik dan Kependidikan pada Pendidikan Formal di Yayasan Pondok Pesantren Mukhtar Syafa'at Blokagung Banyuwangi Nur Khafid Nizam Fahmi, Ahmad Zahidin 
JMPID ( Jurnal Manajemen Pendidikan Islam Darussalam )

Jurnal Manajemen Pendidikan Islam

Volume: 2, No: 2, September 2020

ISSN : 2722-7146 (online)

Edy, Sutrisno. 2009. Manajeman Sumber Daya Manusia. Jakarta: Prenada

Media Group

Hadari, Nawawi. 2005. Manajemen Sumber Daya Manusia untuk Bisnis yang Kompetitif. Yogyakarta: Gajah Mada UniversityPress

Handoko, T. Hani. 2001. Manajemen Personalia dan Sumber Daya Manusia. Yogyakarta: BPFE Yogyakarta

L. Gaol, Chr. Jimmy. 2014. A to Z Human Capital Manajemen Sumber Daya Manusia. Jakarta: PT. Grasindo Anggota Ikapi

Malayu S. P. Hasibuan. 2007. Manajemen Sumber Daya Manusia. Jakarta: Bumi Aksara

Mulyasa. 2010. Implementasi Kurikulum Tingkat Satuan Pendidikan, Jakarta: PT Bumi Aksara

Sofyandi Heman. 2008. Manajemen Sumber Daya Manusia. Yogyakarta: Graha Ilmu

Sugiyono. 2016. Metode Penelitian Kuantitatif, Kualitatif, dan R\&D. Bandung: Alfabeta

Undang-Undang Republik Indonesia No. 20 Tahun 2003 Tentang Sistem Pendidikan Nasional

Sistem Rekrutmen Tenaga Pendidik dan Kependidikan pada Pendidikan Formal di Yayasan Pondok Pesantren Mukhtar Syafa'at Blokagung Banyuwangi Nur Khafid Nizam Fahmi, Ahmad Zahidin 